ASSISTED VENTILATION

\title{
Mechanisms of improvement of respiratory failure in patients with restrictive thoracic disease treated with non-invasive ventilation
}

\author{
A H Nickol, N Hart, N S Hopkinson, J Moxham, A Simonds, M I Polkey

See end of article for authors' affiliations

.

Correspondence to: Dr A Nickol, Osler Chest Unit, Churchill Hospital,

Headington, Oxford OX4 7ப, UK; annabel@medex. org.uk

Received

15 December 2004

Accepted 1 June 2005

Published Online First

6 June 2005

\begin{abstract}
Background: Nocturnal non-invasive ventilation (NIV) is an effective treatment for hypercapnic respiratory failure in patients with restrictive thoracic disease. We hypothesised that NIV may reverse respiratory failure by increasing the ventilatory response to carbon dioxide, reducing inspiratory muscle fatigue, or enhancing pulmonary mechanics.

Methods: Twenty patients with restrictive disease were studied at baseline (D0) and at 5-8 days (D5) and 3 months (3M).

Results: Mean (SD) daytime arterial carbon dioxide tension $\left(\mathrm{PaCO}_{2}\right)$ was reduced from 7.1 (0.9) $\mathrm{kPa}$ to 6.6 $(0.8) \mathrm{kPa}$ at $\mathrm{D} 5$ and $6.3(0.9) \mathrm{kPa}$ at $3 \mathrm{M}(\mathrm{p}=0.004)$, with the mean (SD) hypercapnic ventilatory response increasing from $2.8(2.3) \mathrm{l} / \mathrm{min} / \mathrm{kPa}$ to 3.6 (2.4) $\mathrm{l} / \mathrm{min} / \mathrm{kPa}$ at D5 and $4.3(3.3) \mathrm{l} / \mathrm{min} / \mathrm{kPa}$ at $3 \mathrm{M}$ $(p=0.044)$. No increase was observed in measures of inspiratory muscle strength including twitch transdiaphragmatic pressure, nor in lung function or respiratory system compliance.

Conclusions: These findings suggest that increased ventilatory response to carbon dioxide is the principal mechanism underlying the long term improvement in gas exchange following NIV in patients with restrictive thoracic disease. Increases in respiratory muscle strength (sniff oesophageal pressure and sniff nasal pressure) correlated with reductions in the Epworth sleepiness score, possibly indicating an increase in the ability of patients to activate inspiratory muscles rather than an improvement in contractility.
\end{abstract}

D omiciliary nocturnal non-invasive ventilation (NIV) is a well established treatment for patients with symptomatic hypercapnic respiratory failure secondary to restrictive thoracic disease. NIV has been shown to alleviate symptoms of headache and daytime somnolence, improve intellectual capacity, ${ }^{1}$ reduce hospital admissions, ${ }^{2}$ increase exercise tolerance, ${ }^{3}$ and improve gas exchange. ${ }^{134}$ Furthermore, subsequent studies with long term follow up have shown that improved gas exchange and control of symptoms are maintained for up to 5 years $^{25}$ with the majority of patients continuing NIV. In contrast, a study in which NIV was withdrawn from patients established on treatment led to recurrence of daytime somnolence, morning headaches, reduced energy, and dyspnoea at rest.

It is intriguing that a treatment delivered at night should result in an improvement in symptoms and physiological measures during the day. Despite the widespread use of NIV, the mechanism by which ventilatory failure is reversed is not fully understood. In 1993 Hill proposed three hypotheses by which NIV might work: ${ }^{7}$ (1) it may increase ventilatory sensitivity to carbon dioxide during spontaneous breathing; (2) it may rest fatigued respiratory muscles so increasing their strength and endurance; and (3) it may improve pulmonary mechanics by increasing compliance and lung volumes. Such changes would improve gas exchange by optimising the load/capacity/drive balance of the respiratory system. A number of studies have assessed these proposed mechanisms in isolation but few studies have examined all three hypotheses simultaneously, ${ }^{8}$ making understanding of the interrelationship between these mechanisms limited. Furthermore, due to their invasive nature and complexity, non-volitional assessment of respiratory muscle strength (independent of patient effort) and detailed assessment of respiratory system compliance have not previously been performed in patients with restrictive thoracic disease receiving NIV. The aim of this study was to investigate these hypotheses concurrently to determine the relative importance of each mechanism.

\section{METHODS}

Consecutive restrictive patients with symptomatic hypercapnic respiratory failure, admitted to hospital for 5-8 days for elective nocturnal NIV by a multidisciplinary team, were invited to participate in the study. Ventilators were chosen according to availability and generally set up in pressure control mode (mean (SD) inspiratory pressure 20.9 (4.8) $\mathrm{cm} \mathrm{H}_{2} \mathrm{O}$ ). Three types of ventilators were used: NIPPY $\mathrm{l}(\mathrm{n}=9, \mathrm{~B} \& \mathrm{D}$ Electromedical, Stratford upon Avon, UK), VPAP II ST ( $\mathrm{n}=4$, ResMed, Oxford, UK), and BREAS PV 403 ( $\mathrm{n}=7$, BREAS Medical, Mölnlycke, Sweden). Patients participated in physiological studies at baseline (D0), 58 days (D5), and 3 months after commencing NIV (3M). On each occasion clinical assessment was carried out and symptoms of respiratory failure and subjective sleepiness using the Epworth sleepiness score (ESS) were assessed. Gas exchange was assessed by measuring daytime arterial blood gas tensions (after 20 minutes rest seated breathing air), overnight pulse oximetry $\left(\mathrm{SaO}_{2}\right.$, pulse oximeter 200-E, Nellcor, Pleasanton, USA) and transcutaneous $\mathrm{CO}_{2}\left(\mathrm{PtcCO}_{2}\right.$, Radiometer A/S, Copenhagen, Denmark). Ventilator pressures were titrated upwards as tolerated to control nocturnal

Abbreviations: ESS, Epworth sleepiness score; $\mathrm{FEV}_{1}$, forced expiratory volume in 1 second; FRC, functional residual capacity; FVC, forced vital capacity; HCVR, hypercapnic ventilatory response; NIV, non-invasive ventilation; $\mathrm{PaCO}_{2}$, arterial carbon dioxide tension; $\mathrm{PaO}_{2}$, arterial oxygen tension; PeMax, maximum expiratory mouth pressure; Pga, cough gastric pressure; $\mathrm{PiMax}$, maximum inspiratory mouth pressure; $\mathrm{PtcCO}_{2}$, transcutaneous $\mathrm{CO}_{2}$ - pressure; SNIP, sniff nasal inspiratory pressure; Sniff Pdi, sniff transdiaphragmatic pressure; Sniff Poes, sniff oesophageal pressure; TwPdi, twitch transdiaphragmatic pressure 
hypoventilation by ensuring there was a fall in both peak nocturnal $\mathrm{PtcCO}_{2}$ and daytime $\mathrm{PaCO}_{2}$. Mean hours of use per night was determined at D5 by averaging the use during preceding 3-4 night recorded by ward nursing staff, and at $3 \mathrm{M}$ using the ventilator's hour counter. With the exception of standard lung function, all testing was performed at the same time of day for each patient, starting at either 10.00 hours or 14.00 hours, and took approximately 2.5 hours. Apart from measurements of compliance, all data were acquired, stored, and analysed on a Macintosh computer using customised software (Labview, National Instruments, Austin, TX, USA). Patients refrained from caffeine for at least 2 hours before the start of the tests. The following tests were carried out at D0, D5 and 3M.

The hypercapnic ventilatory response (HCVR) was determined using a rebreathing technique. ${ }^{10}$ With oesophageal and gastric balloon pressure catheters in situ, the following measures of respiratory muscle strength were determined as described previously: ${ }^{11}$ sniff nasal inspiratory pressure (SNIP), sniff oesophageal pressure (Sniff Poes), maximum inspiratory mouth pressure (PiMax), maximum expiratory mouth pressure (PeMax), cough gastric pressure (Pga), sniff transdiaphragmatic pressure (Sniff Pdi), and twitch transdiaphragmatic pressure (TwPdi), assessed using bilateral anterolateral phrenic nerve magnetic stimulation. Full pulmonary function was measured at D0 and $3 \mathrm{M}$ (lung volumes by spirometry and body plethysmography and carbon monoxide transfer factor), and lung volumes by body plethysmography alone at D5. Static lung and chest wall compliance were determined on all three occasions using a quasi-static technique and standard lung function testing equipment and software (Jaegar Compact Body, Viasys Systems Ltd, Warwickshire, UK).

Table 1 Baseline characteristics of patients with neuromuscular weakness and kyphoscoliosis, and statistical difference between the two groups

\begin{tabular}{|c|c|c|c|}
\hline Characteristics & $\begin{array}{l}\text { Neuromuscular } \\
\text { weakness } \\
(n=12)\end{array}$ & $\begin{array}{l}\text { Kyphoscoliosis } \\
(\mathrm{n}=8)\end{array}$ & $p$ value \\
\hline \multicolumn{4}{|l|}{ Anthropometric data } \\
\hline Sex (M:F) & $9: 3$ & $4: 4$ & \\
\hline Age (years) & $64(14)$ & 56 (14) & 0.23 \\
\hline $\mathrm{BMI}\left(\mathrm{kg} / \mathrm{m}^{2}\right)$ & $28(6)$ & $21(6)$ & 0.041 \\
\hline $\mathrm{PaO}_{2}(\mathrm{kPa})$ & $8.3(1.2)$ & $8.3(1.4)$ & 0.76 \\
\hline $\mathrm{PaCO}_{2}(\mathrm{kPa})$ & $7.2(1.9)$ & $7.2(0.9)$ & 0.76 \\
\hline Peak nocturnal & $9.1(1.3)$ & $9.1(1.7)$ & 0.58 \\
\hline \multicolumn{4}{|l|}{$\mathrm{PtcCO}_{2}(\mathrm{kPa})$} \\
\hline ESS (out of 24) & $10.0(4.2)$ & $8.4(5.2)$ & 0.41 \\
\hline \multicolumn{4}{|l|}{ Muscle strength } \\
\hline PiMax $\left(\mathrm{cm} \mathrm{H}_{2} \mathrm{O}\right)$ & $30(1)$ & $41(14)$ & 0.021 \\
\hline Poes $\left(\mathrm{cm} \mathrm{H}_{2} \mathrm{O}\right)$ & 41 (14) & $47(10)$ & $<0.001$ \\
\hline $\mathrm{PeMax}\left(\mathrm{cm} \mathrm{H}_{2} \mathrm{O}\right)$ & $67(28)$ & $70(30)$ & 0.19 \\
\hline Sniff Pdi $\left(\mathrm{cm} \mathrm{H}_{2} \mathrm{O}\right)$ & $33(24)$ & $78(43)$ & 0.005 \\
\hline TwPdi $\left(\mathrm{cm} \mathrm{H} \mathrm{H}_{2} \mathrm{O}\right)$ & $2.1(3.0)$ & $10.8(7.4)$ & 0.15 \\
\hline \multicolumn{4}{|l|}{ Lung function } \\
\hline TLC (\% predicted) & $62(9)$ & $50(7)$ & 0.09 \\
\hline FRC ( $\%$ predicted) & $73(15)$ & 65 (14) & 0.19 \\
\hline RV (\% predicted) & $92(28)$ & $87(21)$ & 0.44 \\
\hline \multicolumn{4}{|l|}{ Static compliance } \\
\hline $\mathrm{C}_{\text {lung }}\left(\mathrm{ml} / \mathrm{cm} \mathrm{H}_{2} \mathrm{O}\right)$ & $85(18)$ & $71(20)$ & 0.048 \\
\hline $\mathrm{C}_{\mathrm{CW}}\left(\mathrm{ml} / \mathrm{cm} \mathrm{H} \mathrm{H}_{2} \mathrm{O}\right)$ & $104(29)$ & $63(26)$ & 0.018 \\
\hline
\end{tabular}

$\mathrm{BMI}$, body mass index; $\mathrm{PaCO}_{2}$, arterial carbon dioxide tension; $\mathrm{PaO}_{2}$, arterial oxygen tension; $\mathrm{PtcCO}_{2}$, transcutaneous $\mathrm{CO}_{2}$ - pressure; ESS, Epworth sleepiness score; PiMax, maximum inspiratory mouth pressure; Poes, oesophageal pressure; PeMax, maximum expiratory mouth pressure; Sniff Pdi, sniff transdiaphragmatic pressure; TwPdi, twitch transdiaphragmatic pressure; TLC, total lung capacity; FRC, functional residual capacity; RV, residual volume; $\mathrm{C}_{\text {Lung, }}$ lung compliance; $\mathrm{C}_{\mathrm{CW}}$, chest wall compliance.
The study was approved by the hospital's ethics committee, and written informed consent obtained.

\section{Data analysis}

All values are expressed as mean (SD) unless otherwise stated. Statistical analysis was carried out using SPSS Version 10 (SPSS Inc, Chicago, USA). Statistical significance was defined as $p<0.05$. One way repeated measures of analysis of variance was used to compare variables measured on the different occasions, linear regression analysis for examination of the relationship between changes in variables, and the Mann-Whitney $U$ test for comparisons of baseline variables between patients with neuromuscular weakness and kyphoscoliosis. All data were normally distributed (KolmogorovSmirnov test).

\section{RESULTS}

\section{Patient characteristics}

Of 21 patients approached, 20 took part in the study; 12 had respiratory neuromuscular weakness and eight kyphoscoliosis. Their characteristics are shown in table 1. Three patients with predominant restrictive disease also had coexisting airways obstruction (two with chronic obstructive pulmonary disease and one with bronchiectasis). Compared with patients with kyphoscoliosis, those with neuromuscular weakness were significantly heavier with a higher body mass index, they had a higher total lung capacity, higher chest wall compliance, and lower lung compliance. By definition, they had reduced respiratory muscle strength.

\section{Use and efficacy of NIV}

Mean (SD) use of NIV was 6.7 (1.9) hours per night at D5 and $4.2(2.6)$ hours per night at $3 \mathrm{M}$. Following NIV there was a significant fall in $\mathrm{PaCO}_{2}(\mathrm{p}=0.004)$, an increase in $\mathrm{PaO}_{2}$ $(p=0.02)$, fall in bicarbonate $(p=0.002)$, and a fall in ESS $\left(\mathrm{p}=0.001\right.$, fig 1). Group nocturnal $\mathrm{PtcCO}_{2}$ and $\mathrm{SaO}_{2}$ are shown in table 2 . Three patients were initiated on supplementary oxygen and their nocturnal $\mathrm{SaO}_{2}$ values are not included. There was a trend towards a reduction towards start of night $\mathrm{PtCCO}_{2}$ and no significant reduction in peak $\mathrm{PtCCO}_{2}$. There was a significant reduction in both the nadir $\mathrm{SaO}_{2}$ and the proportion of the night spent with an $\mathrm{SaO}_{2}$ less than $90 \%$.

\section{Ventilatory response to carbon dioxide}

Following NIV there was a significant increase in HCVR from a mean (SD) of $2.8(2.3) \mathrm{l} / \mathrm{min} / \mathrm{kPa}$ at D0 to 3.6 (2.4) $\mathrm{l} / \mathrm{min} /$ $\mathrm{kPa}$ at D5 and $4.3(3.3) \mathrm{l} / \mathrm{min} / \mathrm{kPa}$ at $3 \mathrm{M}(\mathrm{p}=0.044$, fig 2$)$. There was no relationship between the increase in HCVR and changes in any measures of lung volume (3M FRC: $r^{2}=0.005 ; \mathrm{p}=0.80 ;$ FVC: $r^{2}=0.003 ; \mathrm{p}=0.83$ ) or muscle strength $\left(3 \mathrm{M}\right.$ Sniff Poes: $r^{2}=0.058 ; \mathrm{p}=0.45$; TwPdi: $\left.r^{2}=0.001 ; \mathrm{p}=0.40\right)$.

\section{Respiratory muscle strength}

Measures of respiratory muscle strength are shown in fig 3. Following NIV there was a small but significant increase in one volitional measure of expiratory muscle strength: PeMax increased from $67(28) \mathrm{cm} \mathrm{H}_{2} \mathrm{O}$ to $77(23) \mathrm{cm} \mathrm{H}_{2} \mathrm{O}$ at D5 and $72(29) \mathrm{cm} \mathrm{H}_{2} \mathrm{O}$ at $3 \mathrm{M}(\mathrm{p}=0.04)$. There was a trend towards an increase in one volitional measure of inspiratory muscle strength: sniff Poes increased from 43 (13) $\mathrm{cm} \mathrm{H}_{2} \mathrm{O}$ to 48 (14) $\mathrm{cm} \mathrm{H}_{2} \mathrm{O}$ at $\mathrm{D} 5$ and 53 (11) $\mathrm{cm} \mathrm{H}_{2} \mathrm{O}$ at $3 \mathrm{M}(\mathrm{p}=0.064)$. There were no changes in other measures of respiratory muscle strength. 

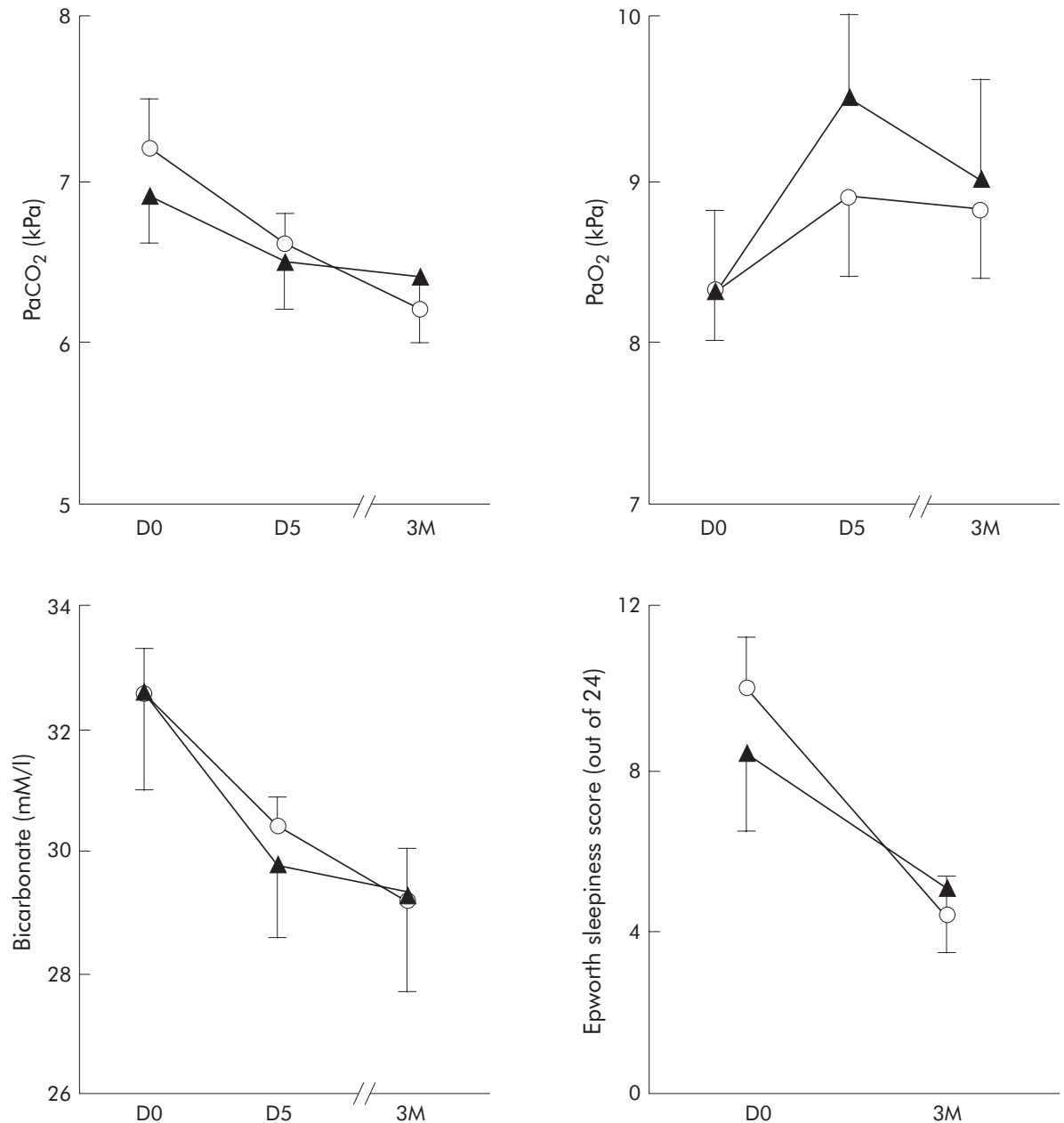

Figure 1 Effect of NIV on arterial blood gas tensions and Epworth sleepiness score (ESS) in patients with neuromuscular weakness (open circles) and kyphoscoliosis (closed triangles). Mean (SE) $\mathrm{PaCO}_{2}, \mathrm{PaO}_{2}$, bicarbonate, and $\mathrm{ESS}$ at day $\mathrm{O}$ (D0), day 5 (D5), and 3 months (3M) are shown. For the group as a whole there was a significant fall in $\mathrm{PaCO}_{2}(p=0.002)$, bicarbonate $(p=0.001)$ and $\mathrm{ESS}(p<0.001)$, and rise in $\mathrm{PaO}_{2}(p=0.02)$.

\section{Pulmonary mechanics}

\section{Lung function}

There were no significant changes in any component of lung function following NIV, including spirometric parameters, lung volumes, and carbon monoxide gas transfer. Of particular importance, given the dependence of respiratory muscle strength on lung volume, there was no group mean change in TLC or FRC. Although some individuals had changes in lung volumes, there was no relationship between changes in FRC and any measures of muscle strength-for example, 3M PiMax: $r^{2}<0.001, \mathrm{p}=0.98$; Sniff Poes: $r^{2}=0.034, \mathrm{p}=0.57$; TwPdi: $r^{2}=0.001, \mathrm{p}=0.93$ ).

\section{Respiratory system compliance}

At baseline, static chest wall compliance was significantly lower in patients with kyphoscoliosis than in those with neuromuscular weakness $\left(53\right.$ (14) $\mathrm{ml} / \mathrm{cm} \mathrm{H}_{2} \mathrm{O} v 106$ (30) $\mathrm{ml} / \mathrm{cm} \mathrm{H}_{2} \mathrm{O} ; \mathrm{p}=0.019$ ), but there was no significant difference in static lung compliance between patients with kyphoscoliosis and those with neuromuscular weak ness (64 (14) $\mathrm{ml} / \mathrm{cm} \mathrm{H}_{2} \mathrm{O} v 85$ (20) $\mathrm{ml} / \mathrm{cm} \mathrm{H}_{2} \mathrm{O} ; \mathrm{p}=0.22$ ). Following NIV there were no significant changes in static lung or chest wall compliance. Group and subgroup values of compliance at D0, D5, and $3 \mathrm{M}$ are shown in table 3 .

Table 2 Mean (SD) nocturnal transcutaneous carbon dioxide pressure $\left(\mathrm{PtcCO}_{2}, \mathrm{n}=20\right)$ and oxygen saturation $\left(\mathrm{SaO}_{2}, \mathrm{n}=17\right)$ at day 0 , day 5 , and 3 months

\begin{tabular}{lllll}
\hline & DO & D5 & 3 M & p value \\
\hline PtccO $_{2}$ start of night (kPa) & $7.5(1.0)$ & $6.7(1.0)$ & $6.6(1.0)$ & 0.09 \\
$\mathrm{PtccO}_{2}$ peak (kPa) & $9.1(1.4)$ & $8.9(3.4)$ & $8.3(1.4)$ & 0.56 \\
$\mathrm{SaO}_{2}$ start of night (\%) & $92(4)$ & $95(3)$ & $93(5)$ & 0.22 \\
$\mathrm{SaO}_{2}$ nadir $(\%)$ & $67(13)$ & $83(6)$ & $79(13)$ & 0.005 \\
Time with $\mathrm{SaO}_{2}<90 \%(\%)$ & $52(30)$ & $12(18)$ & $29(40)$ & 0.035 \\
\hline
\end{tabular}




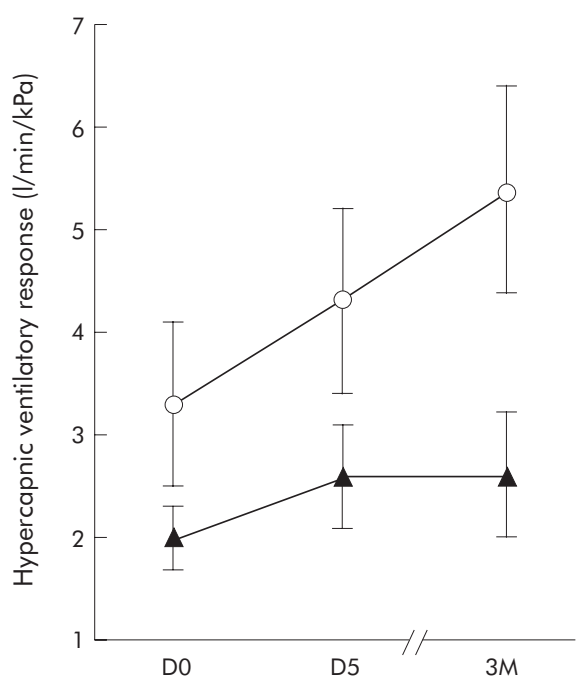

Figure 2 Effect of NIV on hypercapnic ventilatory response (HCVR) in patients with neuromuscular weakness (open circles) and kyphoscoliosis (closed triangles). Mean (SE) HCVR at day 0 (D0), day 5 (D5), and 3 months $(3 M)$ is shown. For the group as a whole there was a significant rise in HCVR $(p=0.04)$.

\section{Comparisons between neuromuscular weakness and kyphoscoliosis groups}

Larger sample sizes would be required for meaningful statistical comparison between the patients with neuromuscular weakness and those with kyphoscoliosis. However, our findings do not suggest any differences in response to NIV between the two subgroups with respect to hours of use, changes in arterial blood gas tensions, drive, or muscle strength (table 4).

\section{"Dose-response" of NIV}

Mean hours of NIV use at 3M was available for 14 patients. At $3 \mathrm{M}$ there was a significant relationship between hours of use and both the decrease in $\mathrm{PaCO}_{2}\left(r^{2}=0.48, \mathrm{p}=0.006\right)$ and decrease in ESS $\left(r^{2}=0.39, \mathrm{p}=0.017\right.$; fig 4$)$. There appeared to be a "threshold effect", with little consistent change in $\mathrm{PaCO}_{2}$ or ESS until NIV had been used for at least 4 hours per night. The same relationship was not observed between hours of use and $\mathrm{PaCO}_{2}$ at D5 $\left(r^{2}=0.08, \mathrm{p}=0.30\right)$. To highlight further the suggestion that HCVR was the principal mechanism underlying reduction in daytime $\mathrm{PaCO}_{2}$, the change in HCVR was divided into those patients using NIV for more than 4 hours per night at $3 \mathrm{M}(\mathrm{n}=9$, mean (SD) use 5.9
(0.8) hours) who were judged to be compliant, and those patients who used NIV for less than 4 hours per night $(n=5$, mean use 1.0 (1.0) hours). At D5, while still in hospital, NIV use was similar and physiological changes in patients who subsequently became compliant and non-compliant at 3 months were comparable. However, at $3 \mathrm{M}$ arterial blood gas tensions, HCVR and respiratory muscle strength had returned to baseline levels in "poor" users, with little change in ESS. Besides the significant relationship between hours of use and decrease in $\mathrm{PaCO}_{2}$ at $3 \mathrm{M}$ described above, there were no significant relationships between changes in $\mathrm{PaCO}_{2}$ and other parameters including HCVR and muscle strength on simple or multiple linear regression.

\section{Relationship between physiological changes and subjective sleepiness}

There was a significant relationship between the fall in ESS and hours of use at $3 \mathrm{M}$ as described above. At $3 \mathrm{M}$ there were also significant relationships between the fall in ESS and increase in two measures of respiratory muscle strength, sniff Poes $\left(r^{2}=0.41, \mathrm{p}=0.02\right)$ and SNIP $\left(r^{2}=0.39, \mathrm{p}=0.005\right)$. There was a trend towards a relationship between ESS and sniff Pdi $\left(r^{2}=0.27, \mathrm{p}=0.10\right)$ and PiMax $\left(r^{2}=0.20\right.$, $\mathrm{p}=0.067$ ), and no relationship with Pgas, TwPdi, or PeMax.

\section{DISCUSSION}

This study examined the three proposed hypotheses by which NIV improves arterial blood gases in patients with symptomatic hypercapnic respiratory failure secondary to restrictive thoracic disease: (1) increased ventilatory sensitivity to $\mathrm{CO}_{2}$, (2) increased respiratory muscle strength, and (3) enhanced pulmonary mechanics. The principal findings support the first hypothesis, with NIV treatment being associated with an increase in ventilatory sensitivity to $\mathrm{CO}_{2}$. Furthermore, the relationship between hours of use and fall in arterial $\mathrm{CO}_{2}$ level and ESS suggests a "dose-response" effect once a threshold of use of approximately 4 hours per night has been reached.

\section{Critique of the method \\ Study design}

It would have been preferable for patients to undergo a standardised run in period for optimisation of medical treatment before commencing NIV, and to have a matched control group who had similar medical contact time and support without NIV. However this was not possible for logistical and ethical reasons. In particular, it would have been difficult to admit patients to hospital without offering NIV. Furthermore, it was not considered ethical to delay
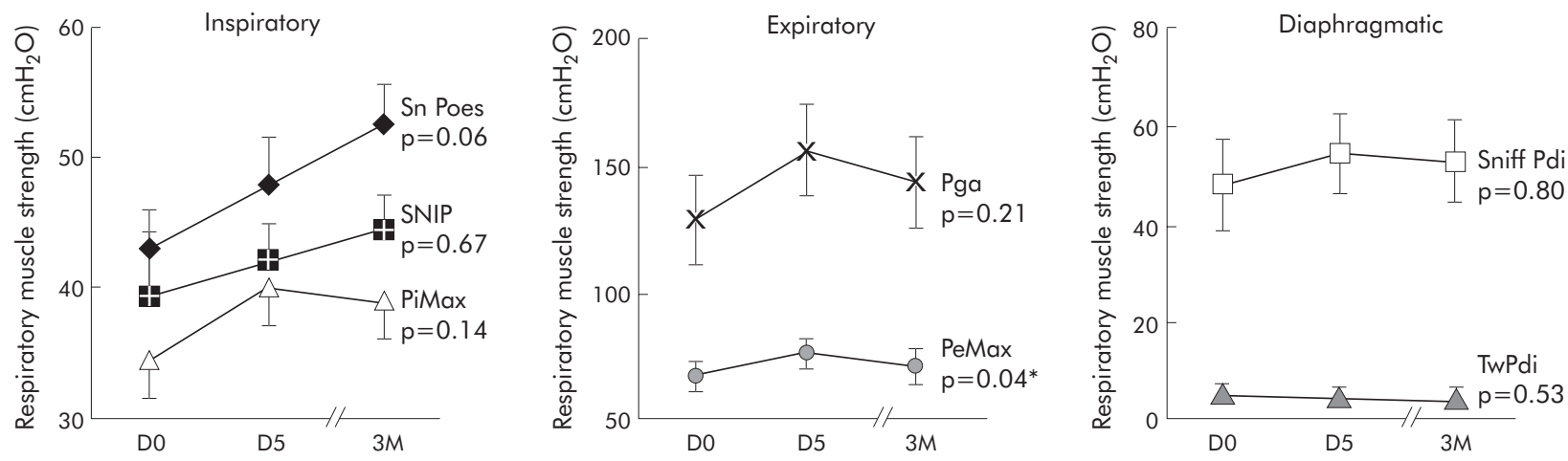

Figure 3 Effect of NIV on inspiratory, expiratory and diaphragmatic respiratory muscle strength. Mean (SE) values at day 0 (D0), day 5 (D5) and 3 months ( $3 \mathrm{M}$ ) are shown. Sniff Poes, sniff oesophageal pressure; PiMax, maximum inspiratory pressure; SNIP, sniff nasal pressure; PeMax, maximum expiratory pressure; Pga, cough gastric pressure; Sniff Pdi, sniff transdiaphragmatic pressure; TwPdi, twitch transdiaphragmatic pressure. Significance values are given. 
Table 3 Mean (SD) static lung and chest wall compliance $\left(\mathrm{ml} / \mathrm{cm} \mathrm{H}_{2} \mathrm{O}\right)$ in the study patients

\begin{tabular}{|c|c|c|c|c|c|c|c|c|}
\hline & \multicolumn{4}{|c|}{ Static lung compliance } & \multicolumn{4}{|c|}{ Static chest wall compliance } \\
\hline & DO & D5 & $3 M$ & p value & DO & D5 & $3 M$ & p value \\
\hline All patients & 80 (19) & $103(35)$ & $96(29)$ & 0.20 & $90(33)$ & $97(43)$ & $98(31)$ & 0.98 \\
\hline Neuromuscular weakness & $85(18)$ & $117(32)$ & $98(31)$ & 0.18 & $104(29)$ & $104(41)$ & $102(30)$ & 0.55 \\
\hline Kyphoscoliosis & $71(20)$ & $72(17)$ & $91(26)$ & 0.12 & $63(26)$ & $80(46)$ & $90(36)$ & 0.25 \\
\hline
\end{tabular}

treatment of the patients for 3 months following assessment. All patients were referred for NIV by external respiratory specialists and had undergone optimisation of medical treatment before entry into the study.

\section{Test reproducibility}

HCVR

There is a high degree of intrinsic variability in HCVR. This was minimised by using the mean of two tests and carrying out testing at the same time of day by the same investigator in a quiet room. In 30 patients with respiratory failure studied on two occasions in our laboratory, there was no significant difference in HCVR between the first and second tests $(2.51 \quad(2.91)$ and $2.65(2.63) \mathrm{l} / \mathrm{min} / \mathrm{kPa}$ respectively, $\mathrm{p}=0.78)$.

\section{Respiratory muscle strength}

In our laboratory there is good long term reproducibility of Sniff Pdi and TwPdi with follow up over 1-5 years in healthy volunteers $^{12}$ and over 1 week to 10 months in patients with normocapnic moderate to severe COPD. ${ }^{13}$ To our knowledge there has not been a study of sequential measurement of TwPdi in patients with severe chest wall deformity and abnormal anatomy of the cervical region. Reasonable reproducibility is suggested by the much greater inter-subject than intra-subject variability on repeat testing at D0, D5, and $3 \mathrm{M}$. Values of TwPdi were small, however, and any genuine physiological changes may have been beyond the resolution of the test.

\section{Respiratory compliance}

We have shown in our laboratory that static lung and chest wall compliance measurements are useful in identifying physiological differences between diagnostic groups; however, it is possible that this technique is not sufficiently sensitive to detect small within subject changes. Despite this, the absence of changes in lung volumes makes it unlikely that significant changes in compliance occurred.

\section{Significance of findings}

\section{Use and efficacy of NIV}

In our patient group NIV resulted in a significant improvement in daytime arterial blood gas tensions and a reduction in subjective sleepiness. In contrast to most previous studies, we did not exclude patients with combined restrictive and obstructive ventilatory defects because such patients are common in clinical practice. Our patient group is therefore likely to include individuals who are more challenging to ventilate successfully, but perhaps to be more representative of the wider population of patients with respiratory failure. Greater NIV use at D5 than 3M may reflect several factors. In the early days in hospital there may be greater patient motivation due to high expectations of a new treatment and intensive support from the multidisciplinary team. In addition, nurses may select the start and end times of NIV use. Later on at home NIV use may reduce as patients determine the optimal balance between symptomatic benefit and NIV tolerability for them.

\section{Increased ventilatory sensitivity to $\mathrm{CO}_{2}$}

HCVR increased significantly following NIV. Such an increase in the ventilatory response to $\mathrm{CO}_{2}$ enables a more appropriate increase in ventilation to occur in response to transient increases in $\mathrm{PaCO}_{2}$, so diminishing hypercapnia. It is likely that the increase in HCVR is brought about by reduced renal retention of bicarbonate, so reducing acid buffering capacity. In this way chemoreceptors could be "reset" to become responsive at a lower level. The increase in HCVR appeared to be directly attributable to an increase in central ventilatory drive rather than to "unmasking" of drive, since it occurred independently of changes in lung volumes, respiratory muscle strength, or compliance. It is, of course, also possible that the improvement in HCVR is due to a small increase in capacity and reduction in load, which in isolation are not significant but in combination have a much larger effect. Multiple linear regression of measures of capacity and load with HCVR were not significant; however, our study was not powered to examine this relationship. Our findings are

Table 4 Mean (SD) values of hours of use, arterial blood gas tensions, Epworth sleepiness score (ESS), hypercapnic ventilatory response (HCVR), and two measures of inspiratory muscle strength in patients with neuromuscular weakness and kyphoscoliosis at DO, D5 and $3 M$

\begin{tabular}{|c|c|c|c|c|c|c|}
\hline \multirow[b]{2}{*}{ Variable } & \multicolumn{3}{|c|}{ Neuromuscular weakness $(n=12)$} & \multicolumn{3}{|c|}{ Kyphoscoliosis ( $n=8$ ) } \\
\hline & DO & D5 & $3 M$ & DO & D5 & $3 M$ \\
\hline Hours & - & $6.3(1.7)$ & $4.4(2.3)$ & - & $7.3(2.2)$ & $3.8(3.9)$ \\
\hline $\mathrm{PaCO}_{2}(\mathrm{kPa})$ & $7.2(0.9)$ & $6.6(0.8)$ & $6.2(0.8)$ & $6.9(0.8)$ & $6.5(0.9)$ & $6.4(1.1)$ \\
\hline $\mathrm{PaO}_{2}(\mathrm{kPa})$ & $8.3(1.2)$ & $8.9(1.6)$ & $8.8(1.3)$ & $8.3(1.4)$ & $9.5(1.3)$ & $9.0(1.8)$ \\
\hline Bicarbonate (mM/l) & $32.6(2.5)$ & $30.4(1.7)$ & $29.2(3.2)$ & $32.6(4.4)$ & $29.8(3.4)$ & $29.3(4.5)$ \\
\hline ESS & $10.0(4.2)$ & - & $4.4(3.3)$ & $8.4(5.2)$ & - & $5.1(4.4)$ \\
\hline HCVR $(I / \mathrm{min} / \mathrm{kPa})$ & $3.3(2.8)$ & $4.3(2.9)$ & $5.4(3.6)$ & $2.0(0.9)$ & $2.6(1.3)$ & $2.6(1.6)$ \\
\hline PeMax $\left(\mathrm{cm} \mathrm{H}_{2} \mathrm{O}\right)$ & $68(28)$ & $77(22)$ & $72(31)$ & $68(29)$ & $76(24)$ & $71(27)$ \\
\hline Poes $\left(\mathrm{cm} \mathrm{H} \mathrm{H}_{2} \mathrm{O}\right)$ & $42(14)$ & $44(14)$ & 50 (13) & $47(10)$ & $58(7)$ & $58(4)$ \\
\hline $\mathrm{FEV}_{1}(\%$ predicted) & $44(11)$ & - & $45(11)$ & $36(8)$ & - & $30(5)$ \\
\hline FVC (\% predicted) & 44 (11) & - & 45 (11) & $36(8)$ & - & $30(5)$ \\
\hline
\end{tabular}



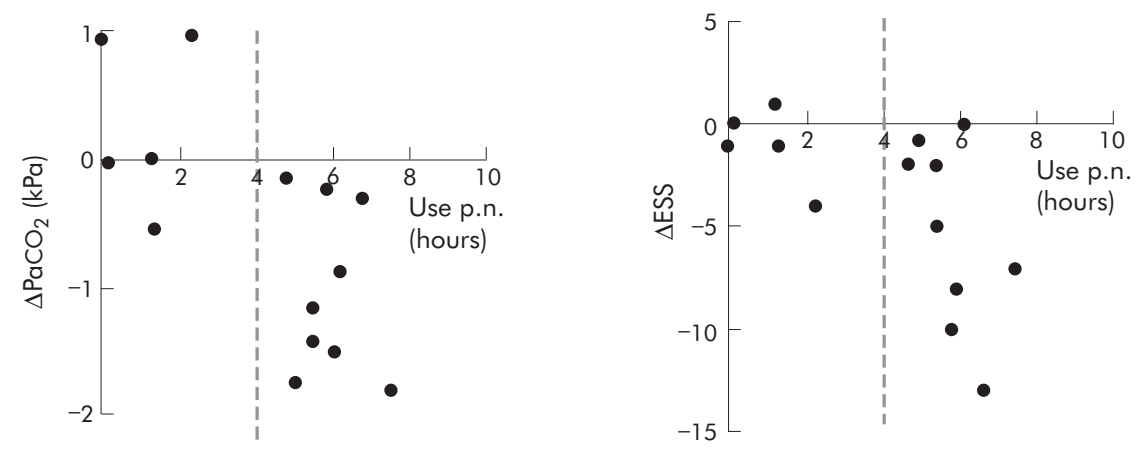

Figure 4 "Dose-response" of NIV: the change in $\mathrm{PaCO}_{2}$ (left panel) and ESS (right panel) at $3 \mathrm{M}$ compared to baseline with mean hours of use is shown for individual patients. There was a significant relationship both for $\mathrm{PaCO}_{2}\left(r^{2}=0.48, p=0.006\right)$ and $\mathrm{ESS}\left(r^{2}=0.39, p=0.017\right)$. The grey dotted line denotes a threshold of NIV use below which NIV does not appear to have a consistent effect upon $\mathrm{PaCO}_{2}$ and subjective sleepiness.

similar to those of Annane and colleagues ${ }^{8}$ but not to those of Dellborg et al. ${ }^{9}$ This may be attributable to the fact that patients in this latter study had a higher baseline HCVR of $3.8 \mathrm{l} / \mathrm{min} / \mathrm{kPa}$ compared with $2.9 \mathrm{l} / \mathrm{min} / \mathrm{kPa}$ in our own study.

There was a non-significant trend for the increase in HCVR to be associated with a decrease in $\mathrm{PaCO}_{2}$ in compliant patients at $3 \mathrm{M}$. This suggests that $\mathrm{PaCO}_{2}$ may be determined in part by the ventilatory response to $\mathrm{CO}_{2}$, but is likely also to be dependent on other factors. This is not surprising since, even when HCVR is increased by over $50 \%$ at $3 \mathrm{M}$, it is still markedly subnormal compared with healthy controls, enabling $\mathrm{PaCO}_{2}$ to fluctuate, albeit around a lower mean value than before initiation of NIV. The relationship between HCVR and $\mathrm{PaCO}_{2}$ is also weakened by the intrinsic variability of both these measures. Annane et $a l^{8}$ found a significant relationship between changes in HCVR and $\mathrm{PaCO}_{2}$ following NIV, but their analysis was carried out in a different way: repeated testing was carried out at 6 months, 1, 2, and 3 years and the maximum change for each individual was used rather than all data at a given time interval. Our data were not analysed in this way as it might have introduced a more favourable bias rather than giving a true reflection of the changes at a given time interval. Dellborg et $a l^{9}$ found no correlation between changes in HCVR and $\mathrm{PaCO}_{2}$.

\section{Changes in respiratory muscle strength}

The second hypothesis regarding the mechanism of action of NIV is that hypercapnic respiratory failure is associated with respiratory muscle fatigue, and that NIV provides muscle rest, so relieving fatigue and increasing muscle strength. We found a significant increase in only one measure of strength, PeMax. Reports of changes in muscle strength in the literature are variable, with some finding no difference in muscle strength ${ }^{8}$ and others isolated increases in single measures. ${ }^{9}$ To our knowledge, ours is the first study to investigate a non-volitional measure of respiratory muscle strength, and it is of interest that there was no change in TwPdi. To our knowledge, ours is also the first study to examine the relationship between changes in muscle strength and subjective sleepiness. Although the ESS has not been formally validated in patients with hypercapnic respiratory failure, previous investigators have observed it to fall in this patient group following NIV. ${ }^{14}$ We found a significant correlation (sniff Poes and SNIP) and trend towards correlation (sniff Pdi and PiMax) of measures of global inspiratory strength with ESS.

The respiratory muscle strength data do not support the respiratory muscle fatigue hypothesis since only one measure of expiratory muscle strength and no measures of inspiratory or transdiaphragmatic strength changed significantly. This hypothesis cannot be completely rejected, however, since respiratory muscle endurance was not tested. The absence of change in respiratory muscle strength may have two underlying explanations. Firstly, it may not be possible for patients with neuromuscular weakness to undergo an increase in muscle strength. Secondly, it has been suggested that fatigue of respiratory muscles is avoided by alteration in breathing pattern by the central nervous system. ${ }^{15}$ The relationship between ESS and several volitional measures of respiratory muscle strength but not TwPdi is of interest. It may be interpreted as showing an increased ability to activate the respiratory muscles rather than improved contractility per se. This could arise due to a greater sense of "well being" enabling more effort to be applied. Against this, however, Hill et $a l^{6}$ found no decrements in respiratory muscle strength following withdrawal of NIV from patients established on it for respiratory failure, despite a recurrence of somnolence. It may be that in some way central facilitation occurs following NIV, enabling the patient's effort to be more effectively translated into force.

In this study we did not assess changes in respiratory muscle endurance following NIV, which may be more relevant to sustained respiratory effort in the face of increased respiratory load than respiratory muscle strength. One study has previously examined this relationship and suggested that endurance was increased following NIV. ${ }^{18}$

\section{Optimisation of pulmonary mechanics}

The final hypothesis regarding the mechanism of action of NIV in restrictive disease is that pulmonary mechanics in hypercapnic respiratory failure are disadvantaged due to both chronic hypoventilation and distortion of the thoracic cage, leading to an increase in work of breathing, and that NIV reverses some of these changes so tending to restore the balance between capacity and load of the respiratory system. In our study there were no changes in spirometric parameters, lung volumes, or carbon monoxide transfer factor following NIV. This enables us to be confident that changes in other parameters that may be dependent on lung volume (such as inspiratory muscle strength and HCVR) occurred as primary effects and were not merely secondary to changes in pulmonary mechanics. Our findings are in keeping with most previous studies..$^{4}{ }^{819-21}$ Dellborg and coworkers ${ }^{9}$ observed a small but statistically significant increase in vital capacity from 1.2 to $1.3 \mathrm{l}$, the clinical significance of which is not entirely clear. In the current study no significant changes in static compliance were observed in the group as a whole or in the subgroups of patients; however, it is interesting to note that there was a greater numerical increase in static lung compliance in patients with neuromuscular weakness and greater numerical increase in static chest wall compliance in patients with kyphoscoliosis. It is likely that numbers of 
patients were too small to show significant differences within the subgroups. In addition, the reproducibility of static lung compliance in patients with critically compromised respiratory function may be insufficient to detect small changes. Simonds et al ${ }^{22}$ have previously compared intermittent hyperinflation for 5 minutes 2-3 times a day for 3 months using either volume or pressure preset ventilation in patients with kyphoscoliosis. They found that volume but not pressure preset ventilation resulted in a significant increase in vital capacity. Since respiratory muscle strength remained unchanged, this was thought to be due to an increase in compliance of the respiratory system. The improvement with volume but not pressure preset ventilation was thought to be due to the higher inspiratory pressures achieved (33 and $30 \mathrm{~cm} \mathrm{H}_{2} \mathrm{O}$, respectively). In our study the mean inspiratory pressure used was $21 \mathrm{~cm} \mathrm{H}_{2} \mathrm{O}\left(22 \mathrm{~cm} \mathrm{H}_{2} \mathrm{O}\right.$ for patients with neuromuscular weakness and $20 \mathrm{~cm} \mathrm{H}_{2} \mathrm{O}$ for patients with kyphoscoliosis). It seems likely that higher inflation pressures and transient hyperinflation is necessary to increase respiratory system compliance.

\section{Conclusions}

In conclusion, this study confirms that NIV is an effective treatment in patients with symptomatic hypercapnic respiratory failure secondary to restrictive disease alone, both in terms of daytime $\mathrm{CO}_{2}$ and sleepiness. It supports the hypothesis that NIV reverses ventilatory failure by increasing the ventilatory response to $\mathrm{CO}_{2}$.

\section{ACKNOWLEDGEMENTS}

The authors thank Steve Heather and the sleep technicians for their care of patients when initiating NIV, Derek Cramer and Simon Ward and lung function staff for overseeing lung function testing and sleep studies, Carl-Hugo Hamnegård for his assistance with Labview ${ }^{\circledR}$ software modification, and Mary Morrell and Ewen Ross for their support.

\section{Authors' affiliations \\ A H Nickol, N Hart, N S Hopkinson, A Simonds, M I Polkey,} Respiratory Muscle Laboratory, Royal Brompton Hospital, London SW3 6NP, UK

J Moxham, Respiratory Muscle Laboratory, Guy's King's and St Thomas' School of Medicine, King's College Hospital, London SE5 9PJ, UK

$\mathrm{AHN}$ and this work was funded by a project grant from the British Lung Foundation, NH by the Dorothy Osbourne Legacy, NSH by the Wellcome Trust, and MIP's group from the European Union (QLK6-CT2002-02285)

Competing interests: AHN has received contributions from GlaxoWellcome, Astra Pharmaceuticals, Cephalon, Medic-Aid and Breas Medical towards the cost of attending professional meetings (ERS, ATS). AS has received research grants from Breas Medical ( $£ 75$ 000) and ResMed ( $£ 62000$ ) to investigate the appropriate time to initiate non-invasive ventilation and inpatient versus outpatient initiation, and the use of a ventilator in patients with congestive heart failure, respectively. These projects are unrelated to the current study. She has received financial support from Cephalon to attend a scientific meeting. MIP has received fees for lecturing from the following companies totalling £2674 between 2003 and 2004: Astra Zeneca, GlaxoSmithKline, Nutricia and Cephalon. He has also attended professional meetings (ERS, ATS, APSS) as a guest of GlaxoWellcome, Astra Zeneca, Cephalon, $3 \mathrm{M}$ and Ciba. NH, NSH and JM have no competing financial interests.

Some of the data presented here have been presented previously in abstract form.

\section{REFERENCES}

1 Kerby G, Mayer L, Pingleton S. Nocturnal positive pressure ventilation via nasal mask. Am Rev Respir Dis 1987;135:738-40.

2 Leger P, Bedicam J, Cornette A, et al. Nasal intermittent positive pressure ventilation. Long-term follow up in patients with severe chronic respiratory insufficiency. Chest 1994;105:1000-5.

3 Carroll N, Branthwaite M. Control of nocturnal hypoventilation by nasal intermittent positive pressure ventilation. Thorax 1988;43:349-53.

4 Ellis E, Grunstein R, Chan S, et al. Noninvasive ventilatory support during sleep improves respiratory failure in kyphoscoliosis. Chest 1988;94:811-5.

5 Simonds A, Elliott M. Outcome of domiciliary nasal intermittent positive pressure ventilation in restrictive and obstructive disorders. Thorax 1995; 50:604-9.

6 Hill NS, Eveloff SE, Carlisle CC, et al. Efficacy of nocturnal nasal ventilation in patients with restrictive thoracic disease. Am Rev Respir Dis 1992; 145:365-71.

7 Hill NS. Noninvasive ventilation. Does it work, for whom, and how? Am Rev Respir Dis 1993;147:1050-5.

8 Annane D, Quera-Salva MA, Lofaso F, et al. Mechanisms underlying effects of nocturnal ventilation on daytime blood gases in neuromuscular diseases. Eur Respir J 1999;13:157-62.

9 Dellborg $\mathrm{C}$, Olofson J, Hamnegard $\mathrm{C}-\mathrm{H}$, et al. Ventilatory response to $\mathrm{CO}_{2}$ rebreathing before and after nocturnal nasal intermittent positive pressure ventilation in patients with chronic alveolar hypoventilation. Respir Med 2000;94: 1154-60.

10 Read D. Clinical method for assessing the ventilatory response to carbon dioxide. Austral Ann Med 1967;16:20-32.

11 Polkey M, Green M, Moxham J. Measurement of respiratory muscle strength. Thorax 1995;50:1131-5.

12 Luo Y, Hart N, Mustfa N, et al. Reproducibility of twitch and sniff transdiaphragmatic pressures. Respir Physiol Neurobiol 2002;132:301-6.

13 Polkey M. The function of the diaphragm in chronic obstructive pulmonary disease, PhD thesis. Department of Respiratory Medicine, King's College School of Medicine and Dentistry, 1997:265.

14 Newsom-Davis I, Lyall R, Leigh P, et al. The effect of non-invasive positive pressure ventilation (NIPPV) on cognitive function in amyotrophic lateral sclerosis (ALS): a prospective study. J Neurol Neurosurg Psychiatry $2001 ; 1: 482-7$

15 Elliott M, Mulvey D, Moxham J, et al. Domiciliary nocturnal nasal intermittent positive pressure ventilation in COPD: mechanisms underlying changes in arterial blood gas tensions. Eur Respir J 1991;1991:1044-52.

16 Demoule A, Verin E, Derenne J-P, et al. Plasticity of the human motor cortical representation of the diaphragm. Am J Respir Crit Care Med 2001;63:A154.

17 Sharshar T, Ross E, Hopkinson N, et al. Depression of diaphragm motor cortex excitability during mechanical ventilation. J Appl Physiol 2004;7:3-10.

18 Goldstein R, Rosle JD, Avendano M, et al. Influence of non invasive positive pressure ventilation on inspiratory muscles. Chest 1991;99:408-15.

19 Gay P, Patel A, Viggiano R, et al. Nocturnal nasal ventilation for treatment of patients with hypercapnic respiratory failure. Mayo Clin Proc 1991;66:695-703.

20 Barbe F, Quera-Salva M, Lattre JD, et al. Long-term effects of nasal intermittent positive pressure ventilation on pulmonary function and sleep architecture in patients with neuromuscular diseases. Chest 1996;110:1179-83.

21 Waldhorn R. Nocturnal nasal intermittent positive pressure ventilation with bilevel positive airway pressure (BiPAP) in respiratory failure. Chest 1992;101:516-21.

22 Simonds A, Parker R, Branthwaite M. The effect of intermittent positivepressure hyperinflation in restrictive chest wall disease. Respiration 1989;55:136-43 